\title{
Coronary Arteries In Pigs ( Sus Scrofa Dom.)- Deep Myocardial Collaterals of Coronary Arteries
}

\author{
Alexandra BLENDEA*, Ioana CHIRILEAN, Aurel DAMIAN \\ Department of Comparative Anatomy, University of Agricultural Sciences and Veterinary Medicine, \\ Faculty of Veterinary Medicine, Cluj-Napoca, 3-5 Mănăştur Street, Romania \\ Corresponding author: blendeaalexandra@gmail.com
}

Bulletin UASVM Veterinary Medicine 72(1) / 2015,

Print ISSN 1843-5270; Electronic ISSN 1843-5378

DOI:10.15835/buasvmcn-vm: 11000

\begin{abstract}
Pig's heart could be used for conducting experiments on coronary arteries. As far as the coronary blood supplyis the heart of the pig was similar to that of man with small differences. The bibliografic data are illuminating taking into consideration the multiple origin variations of the coronary arteries (Edward-Luisada-HollisheadKlein, quoted by Pop D. Popa, 1982), and then the observations concerning the representation of the percentage of different origin' versions of the cardiac vessels (Wernaeky quoted by Agneoletti et al., 2005), anatomical particularities of the cardiac vessels in human (Pop D. Popa, 1982).

The study has been conducted on a total of seven hearts harvested from adult pigs, common breads, slaughtered for economic purposes by exsanguination, considered clinically healthy. The orifices of the heart arteries - coronary left and right were found after opening the aortic bulb. The product PALUX colored with red pigment was injected in the arterial lumen. Segmental photos were taken during the dissection of the vascular tracks.

The left coronary artery in the initial trajectory segment releases deep collaterals for the left atrium and pulmonary arterial trunk. The paraconal terminal releases numerous deep collaterals which particularly irrigate the front of the adjacent right ventricle. The circumflex terminal releases left arterial dorsal deep collaterals, and the deep branches emerge from the intermediate arteries. The right coronary artery releases numerous fine dorsal branches, which penetrate the walls of the right atrium. The right ventricular deep collaterals are released from the superficial ventricular arteries.

In addition to the deep collaterals of the superficial cardiac arteries, also the paraconal artery, the circumflex artery and the right coronary artery release deep direct collaterals for the myocardium and the atrioventricular papillary formations.
\end{abstract}

Keywords: collaterals, coronary arteries, sus scrofa domestica.

\section{INTRODUCTION}

In recent years, several technological progresses in coronary arteries evaluation have been made. Taking into consideration the close resemblance between the porcine heart and the human heart, these experiments help develop new treatments techniques for cardiac pathology. Literature regarding coronary arteries delves deeply in details such as considering several variants of artery origins (Wernaeky quoted by Agneoletti et al., 2005) and anatomical particularities of blood vessels in humans (Pop D. Popa, 1982). We must underline that the present study is part of a $\mathrm{PhD}$ research topic regarding the coronary arteries in pigs.

\section{MATERIALS AND METHODS}

Our study was carried out at the Comparative Anatomy Department if the University of Agricultural Sciences and Veterinary Medicine of Cluj-Napoca, on 7 hearts harvested from clinically healthy domestic pigs of common breed that where 
commercially slaughtered by exsanguination. The hearts were intact, without any vascular damage. Using step-by-step dissection techniques, we opened the aortic bulb, identifying the origin orifices of the right and left coronary arteries. We then injected into the lumina of the arteries the product PALUX mixed with red pigment. After injecting the color mixture, the hearts were immersed in a $10 \%$ formalin solution for fixation. The dissection was performed aproximatively 24 hours afterwards, on which occasion we have also progressively taken segmented photos.

\section{RESULTS AND DISCUSSION}

We have registered several major peculiarities that are obvious and not described by the reference literature: the left coronary artery in the initial trajectory segment releases deep collaterals for the left atrium and pulmonary arterial trunk. The paraconal terminal releases numerous deep collaterals which particularly irrigate the front of the adjacent right ventricle. The circumflex terminal releases left arterial dorsal deep collaterals, and the deep branches emerge from the intermediate arteries. The right coronary artery releases numerous fine dorsal branches, which penetrate the walls of the right atrium. The right ventricular deep collaterals are released from the superficial ventricular arteries.

\section{CONCLUSION}

In addition to the deep collaterals of the superficial cardiac arteries, also the paraconal artery, the circumflex artery and the right coronary artery release deep direct collaterals for the myocardium and the atrioventricular papillary formations.

Acknowledgements. This paper was published under the frame of European Social Fund, Human Resources Development Operational Programme 2007-2013, project no. POSDRU/159/1.5/S/ 136893.

\section{REFERENCES}

1. Agnoletti G, Bajolle F, Bonnet D, Sidi D, Vouche P (2005). Late coronary complication after arterial switch for transposition arteries. Clinical and therapeutic implication. Images Paerdiatr Cardiol 24:1-11.

2. Chirilean I, Damian A, Popovici NC, Stan F, Dezdrobitu C (2010). Specific Anatomical Aspects of the Aortic Opening (Ostium Aortae) and of the Left Cardiac Artery (A: Coronaria Sinistra) in Swine. Bulletin of University of Agricultural Sciences and Veterinary Medicine ClujNapoca, 28-33.

3. James T N (1961). Anatomy of the coronary arteries. Paul B Hoeber, New York

4. Pop D, Popa I (1982). Sistemul arterial aortic. Vol. I. Medicală, București, 34-143.

5. Weaver ME, Pantely GA, Bristow JD, Ladely HD (1986). A quantitative study of the anatomy distribution of coronary arteries in swine in comparison with other animals and man. Cardiovasc Res 20:907-17. 